\title{
The Australian Counterinsurgency Campaign in the Vietnam War: The Ambush Battle
}

Map 1: Enemy Force Size and Relative Strength: 1ATF Ambushes of the Enemy

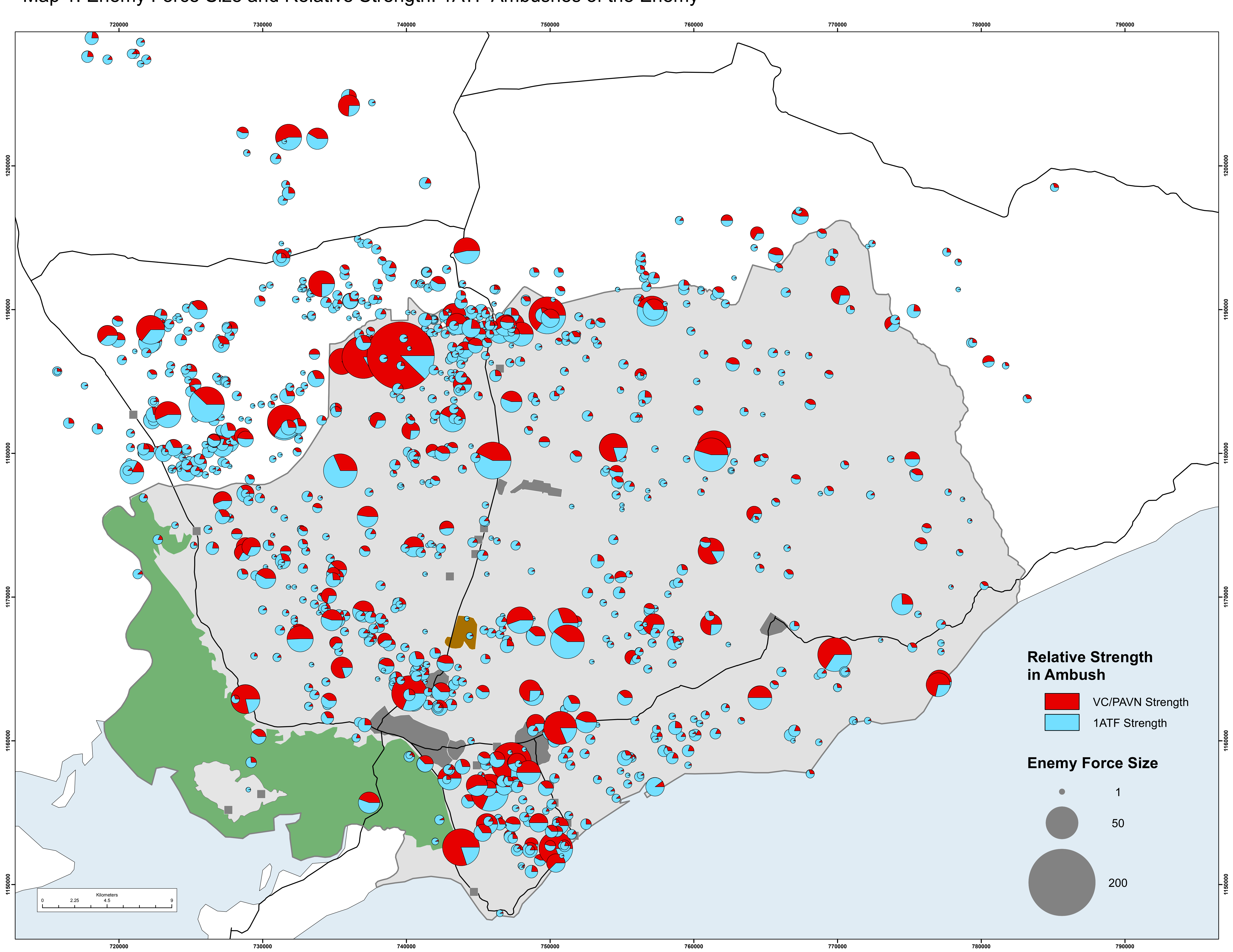

Reference map

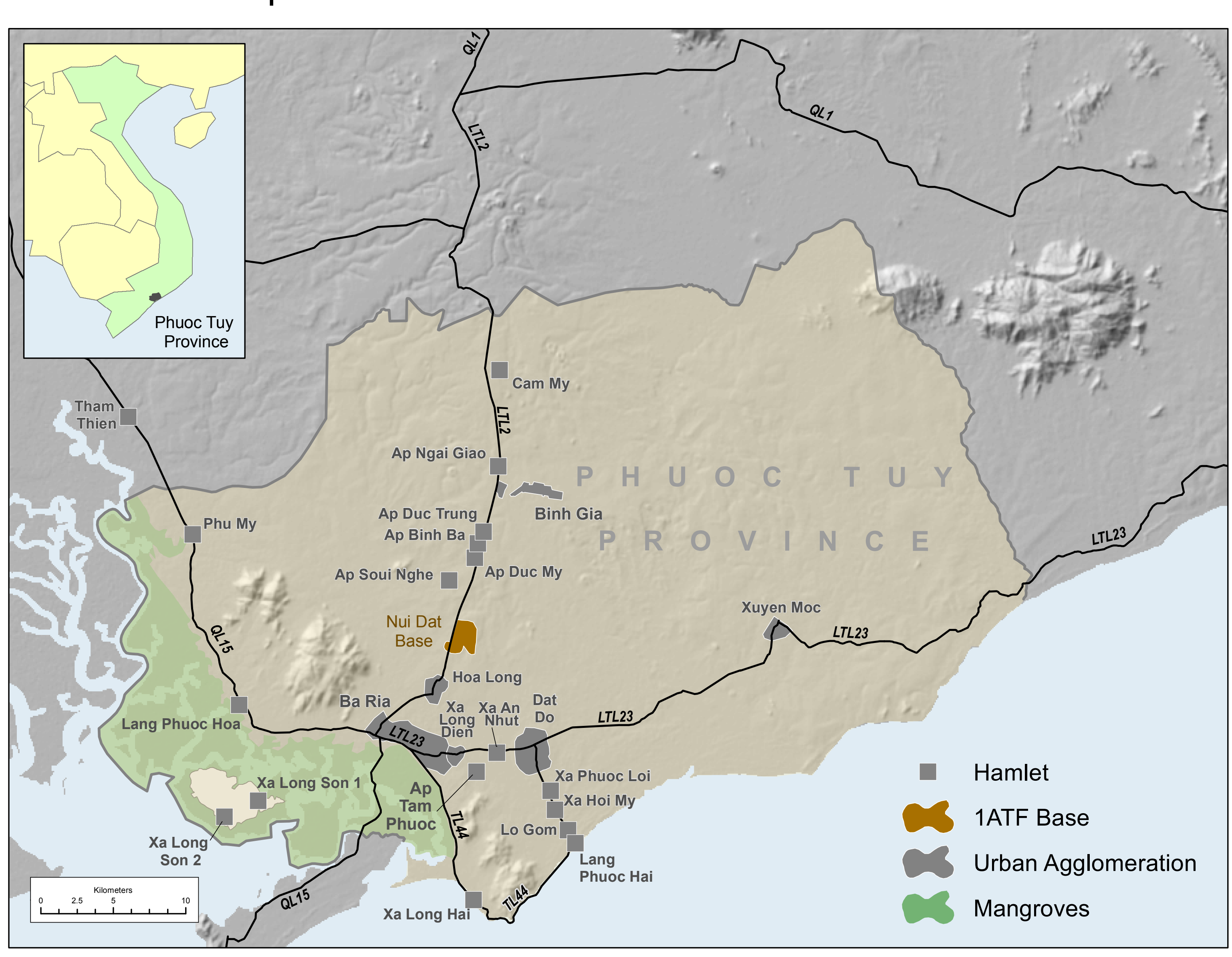

Map 2: 1 ATF attacks on enemy bunker systems

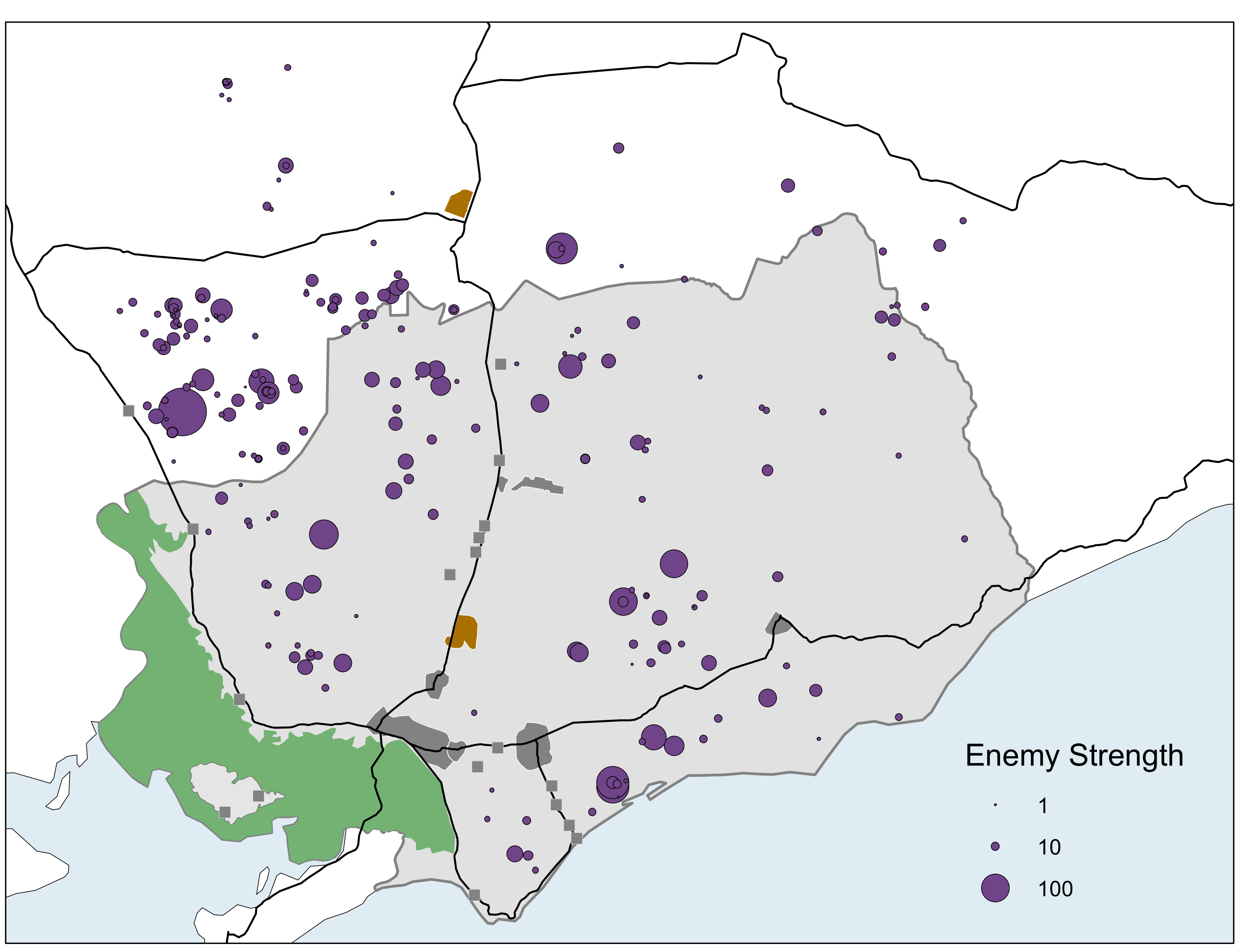

Maps 3-8: 1ATF Ambushes Near Settlements According to Time of Day

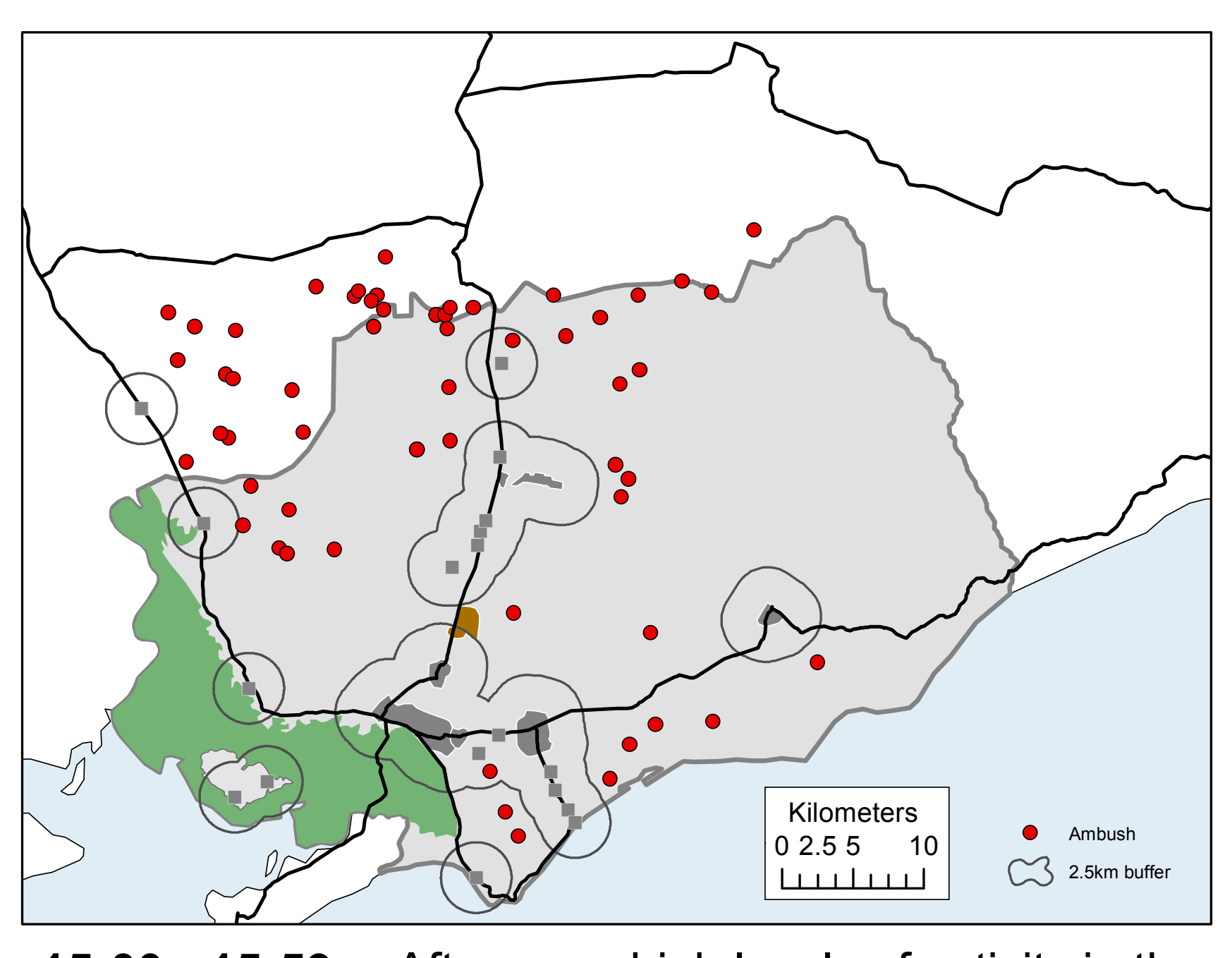

15:00 - 15:59: Afternoon; high levels of activity in the
jungle, little activity near settlements

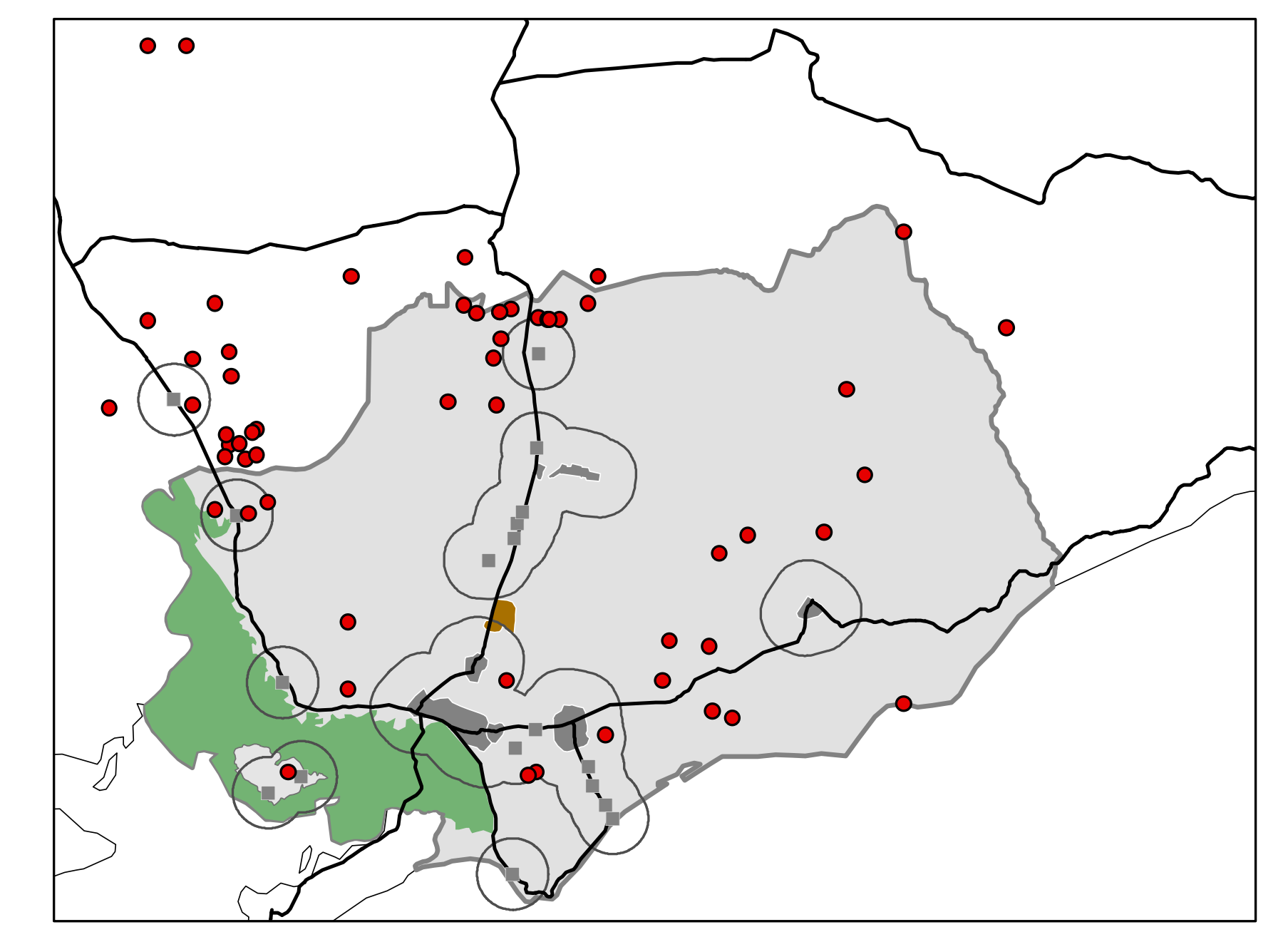

18:00 - 18:59: Nightalli, increasing concentrations
near settlements

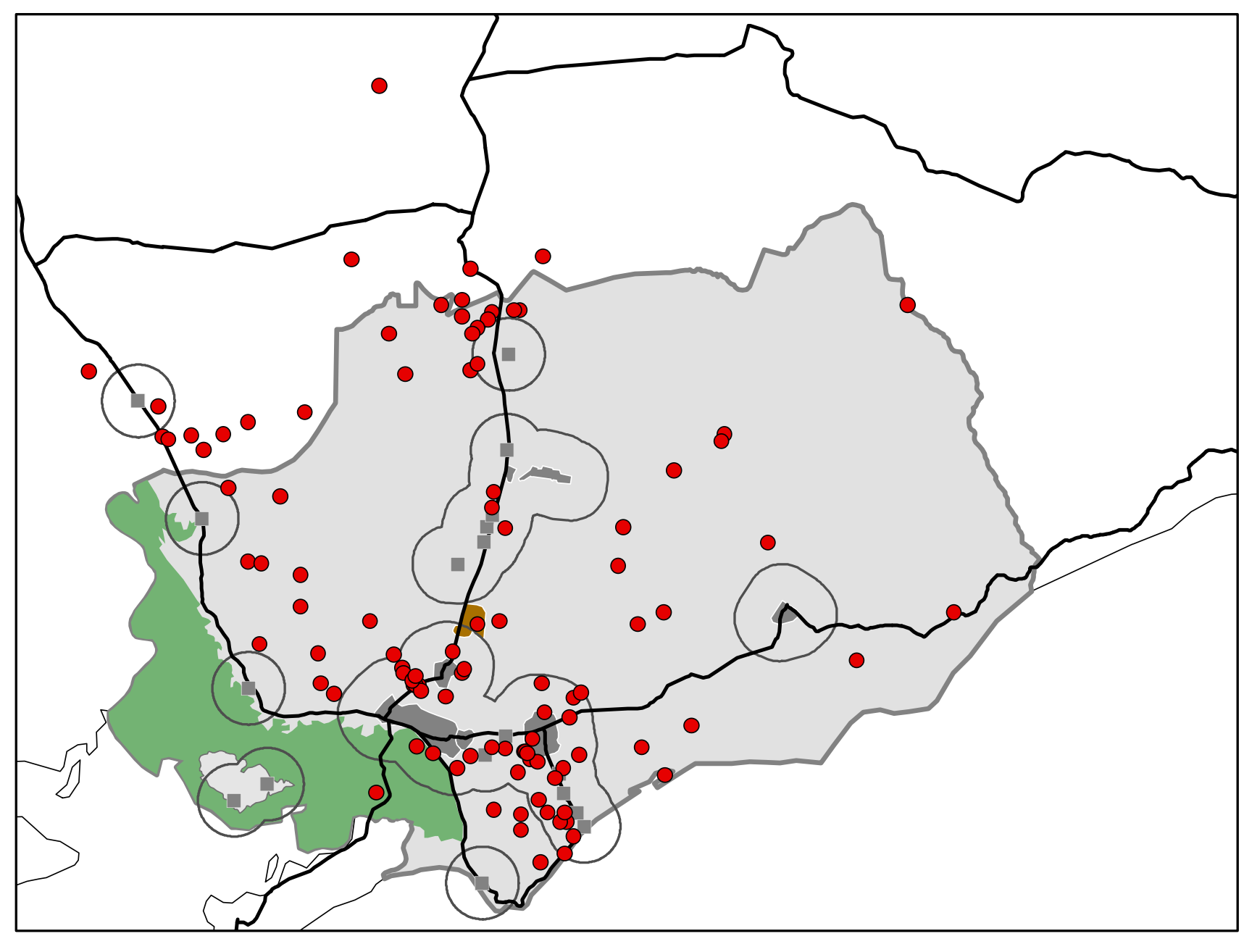

20:00 - 20:59: Night, high concentrations near

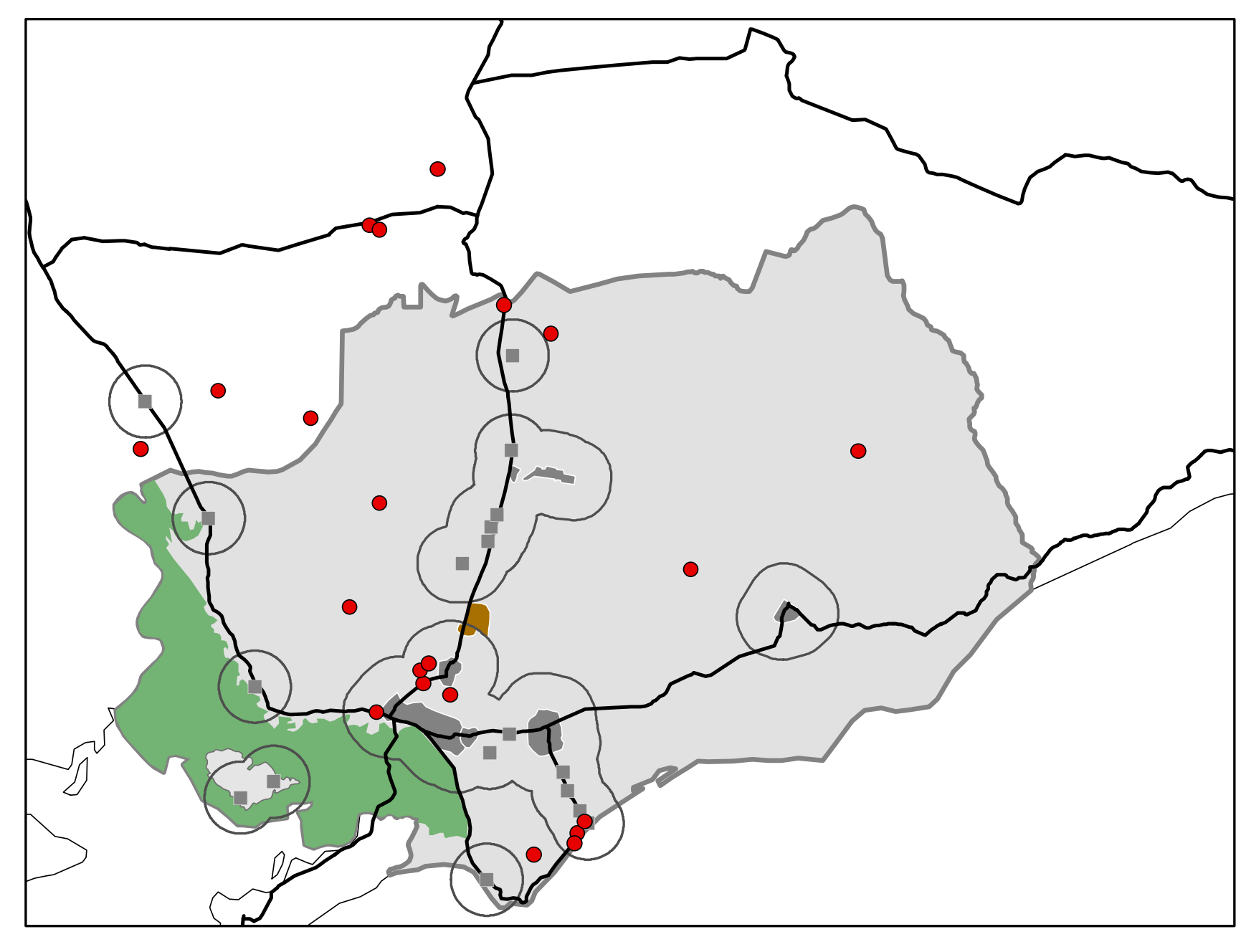

0:00 - 0:59: Around midnight; low levels of ambush

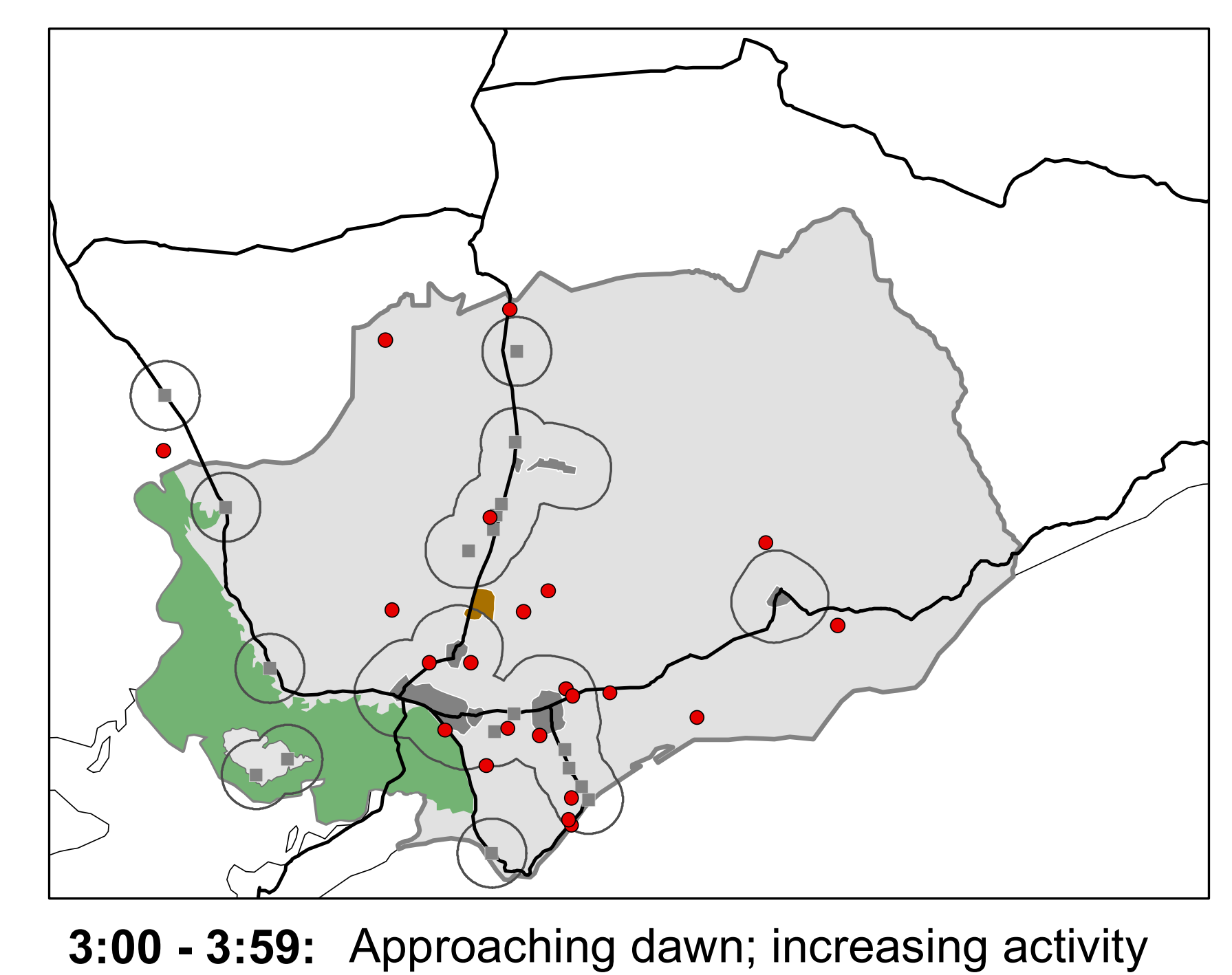

3:00 - 3:59: Approaching dawn; increasing activity
near settlements



6:00 - 6:59: Morning; low activity near settlement
increasing activity in the jungle 